FACTA UNIVERSITATIS

Series: Mechanical Engineering Vol. 16, Nº 2, 2018, pp. 233 - 247

https://doi.org/10.22190/FUME180117024G

Original scientific paper

\title{
HEAT TRANSFER ENHANCEMENT AND PRESSURE DROP FOR FIN-AND-TUBE COMPACT HEAT EXCHANGERS WITH DELTA WINGLET-TYPE VORTEX GENERATORS
}

\author{
UDC 536.2
}

\author{
Seyed Alireza Ghazanfari, Mazlan Abdul Wahid \\ High-Speed Reacting Flow Laboratory, Faculty of Mechanical Engineering, \\ Universiti Teknologi Malaysia, Johor, Malaysia
}

\begin{abstract}
Heat transfer rate, pressure loss and efficiency are considered as the most important parameters in designing compact heat exchangers. Despite different types of heat exchangers, fin-and-tube compact heat exchangers are still common device in different industries due to the diversity of usage and the low space installation need. The efficiency of the compact heat exchanger can be increased by introducing the fins and increasing the heat transfer rate between the surface and the surroundings. Numerous modifications can be applied to the fin surface to increase heat transfer. Delta-winglet vortex generators (VGs) are known to enhance the heat transfer between the energy carrying fluid and the heat transfer surfaces in plate-fin-and-tube banks, but they have drawbacks as well. They increase the pressure loss and this should be considered. In this paper, the thermal efficiency of compact heat exchanger with VGs is investigated in different variations. The angle of attack, the length and horizontal and vertical position of winglet are the main parameters to consider. Numerical analyses are carried out to examine finned tube heat exchanger with winglets at the fin surface in a relatively low Reynolds number flow for the inline tube arrangements. The results showed that the length of the winglet significantly affects the improvement of heat transfer performance of the fin-and-tube compact heat exchangers with a moderate pressure loss penalty. In addition, the results show that the optimization cannot be performed for one criterion only. More parameters should be considered at the same time to run the process properly and improve the heat exchanger efficiency.
\end{abstract}

Key words: Compact heat exchangers, Parametric study, Vortex generators, Heat transfer enhancement.

Received January 17, 2018 / Accepted May 30, 2018

Corresponding author: Seyed Alireza Ghazanfari

High-Speed Reacting Flow Laboratory, Faculty of Mechanical Engineering, Universiti Teknologi Malaysia,

81310 UTM Skudai, Johor, Malaysia

E-mail: Alireza.ghazanfari@gmail.com 


\section{INTRODUCTION}

Nowadays, tube bank fin heat exchangers are commonly exploited in different industrial tools like cooling systems of locomotive engine and chillers. One of the main drawbacks of such heat exchangers is related to their high energy consumption. Thus, in order to mitigate the consumption of energy, there have been efforts on improving the heat transfer in the fin sides. One of the recently known ways of achieving this purpose is making modification on the geometry of the fin surface.

Based on the previous works on approaches to geometry modification, the most outstanding modifications include the wavy fin [1], the slit fin [2], the louvered fin [3], the interrupted annular groove fin [4], the fin with winglet-type vortex generators (VGs) [5], and some combination enhanced fins [6, 7].

One of the well-established approaches for improving the heat transfer in fin side is creating a secondary flow with VGs. It functions by both making interruption in development of thermal boundary layer and creating longitudinal vortices, which improves the moment and mass transfer of fluid between the area close to the wall and the region remote from the wall.

Fiebig [8] and Jacobi and Shah [9] conducted a review study on exploitation of VGs in compact heat exchangers. Their studies have shown that plain winglet VGs consisting of delta-winglet [10-15] and rectangular-winglet [16] are considered as the most prevalent applications.

Based on the result from the comparative study done by Tiggelbeck et al. [17], delta winglets and the rectangular winglets are considered as the highest and second highest performance respectively. In a similar way, $\mathrm{He}$ et al. [18] made a comparison on the performance of delta-winglet pairs consisting of two layout styles (continuous and discontinuous) with that of the traditional large winglet.

Based on the results, discontinuous oriented winglets are found to be the best heat transfer improvement mode. In a similar study done by Torri et al. [19], delta winglet-type VGs are applied, which has led to eliminating areas with poor heat transfer around wake of the tube.

In the other study related to the application of VGs in heat transfer, Lin et al. [20, 21] analyzed flow features of heat exchangers which are fitted with wave-type, annular and inclined formed VGs. In another research by Leu et al. [22] thermal-hydraulic features of inlined and staggered plate fin-tube heat exchangers were studied through investigation of block styled VGs fitted behind the tubes, which indicated optimization of the VG's span angle and the VG's transverse place.

Dupont et al. [23] did an empirical study on flow characteristics by exploiting embossedtype VGs which were cyclically arranged. They demonstrated that the application of such forms of VGs could be the striking point in the area of heat transfer enhancement.

Ye et al. [24] compared the performance of curved trapezoidal winglet VGs with that of conventional plain VGs consisting of rectangular-winglet, trapezoidal-winglet and deltawinglet forms. According to the results, the delta winglet mode is observed as the best form under laminar and transitional flow condition. On the other hand, under the turbulent condition, curved trapezoidal winglet has shown the best performance. It should be noted that in spite of its superiority, it is not commonly used in tube bank fin heat exchangers existing on the market.

Based on the current research stream on the heat transfer enhancement of the compact heat exchangers, VGs are basically applied to create vortices. Besides, in some studies, they have been exploited to put the flow in the right direction. Therefore, due to the existence of wake 
area behind tubes, VGs can be taken granted with two different functions including generating vortex and directing flows. However, identifying the optimal design should be an important issue requiring sober consideration. For instance, plane VGs are found to be fitted on the fine surface, while other block styled VGs do not fit in this format. Therefore, this study has adopted a delta-winglet VG which is fitted on the fin surface as demonstrated in Fig. 1.

By applying the proposed VG pattern, this study tries to direct fluid flow to the tube wake areas, which is likely to improve the weak heat transfer on the fin surfaces that are in touch with the wake area. Yet, it is expected that the produced vortices can improve the transfer in a big area of the fin surface. To achieve the main objective of this study, a numerical method is conducted to examine how delta winglet vortex generators function. In the next section, first, the physical model and numerical formulation are introduced, and then the results from analyses of fluid flow features are explained.

\section{NUMERICAL SETUP}

\subsection{Geometry}

The solution domain describes the approximate location where the solution is performed. The shape of the domain can be rectangular. Most of the previous literatures show that rectangular domain is the best for this case [25]. The main parameters of the FTCHE are specified in Table 1 and shown in Fig. 1.
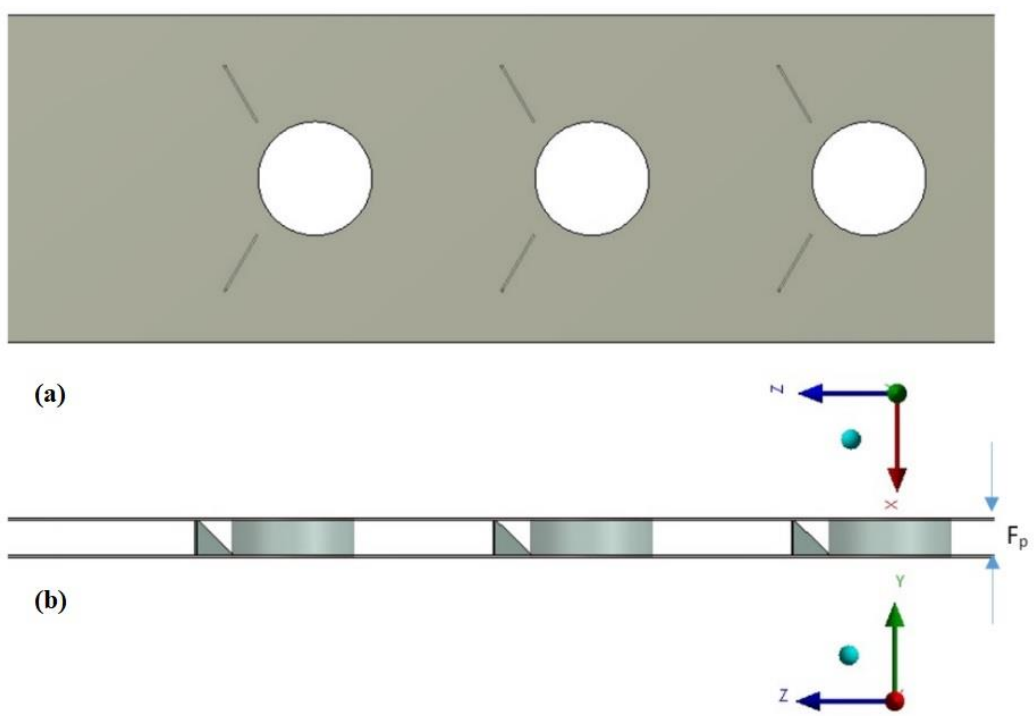

Fig. 1 Solution domain (a) top view, (b) side view 
Table 1 Detailed geometry parameters of based FTCHE with delta winglet

\begin{tabular}{lcc}
\hline Parameter & Symbol (unit) & Value \\
\hline Transverse tube spacing & $\mathrm{P}_{\mathrm{t}}(\mathrm{mm})$ & 25.4 \\
Longitudinal tube spacing & $\mathrm{P}_{1}(\mathrm{~mm})$ & 25.4 \\
Fin pitch & $\mathrm{F}_{\mathrm{p}}(\mathrm{mm})$ & 3.0 \\
Fin thickness & $\delta_{\mathrm{f}}(\mathrm{mm})$ & 0.2 \\
Fin length & $\mathrm{F}_{1}(\mathrm{~mm})$ & 101.6 \\
Fin width & $\mathrm{F}_{\mathrm{w}}(\mathrm{mm})$ & 25.4 \\
Tube position from the inlet & $\mathrm{X}_{\mathrm{l}}(\mathrm{mm})$ & 12.7 \\
Number of tubes & $\mathrm{N}$ & 4 \\
Angle of attack & $\theta($ degree $)$ & 30 \\
Length of the VG & $l(\mathrm{~mm})$ & 6 \\
Horizontal Position of VG & $X_{v}(\mathrm{~mm})$ & 5.275 \\
Vertical Position of VG & $Y_{v}(\mathrm{~mm})$ & 5.275 \\
\hline
\end{tabular}

\subsection{Boundary conditions}

The complete details of boundary conditions were simulated in this study to investigate the thermal and fluid dynamic characteristics that are used in ANSYS FLUENT are described as follows:

- Inflow: velocity inlet;

- Outflow: outflow;

- Side Wall: wall;

- Top and bottom fins: symmetry;

- Tube walls: no-slip walls

- Fluid domain: FLUID

\subsection{Governing equations}

The general form of the continuity and Naiver-Stokes equations with Reynolds averaging [26] are used along with the k- $\varepsilon$ model equation as explained below. Based on the study conducted by Ferrouillat et al. [27], k- $\varepsilon$ is well capable of predicting the flow behaviour.

$$
\begin{gathered}
\frac{\partial k}{\partial t}+U_{i} \frac{\partial k}{\partial x_{i}}=v_{t}\left(\frac{\partial U_{i}}{\partial x_{j}}+\frac{\partial U_{j}}{\partial x_{i}}\right) \frac{\partial U_{i}}{\partial x_{j}}-\varepsilon+\frac{\partial}{\partial x_{j}}\left[\left(v+\frac{v_{t}}{\sigma_{k}}\right) \frac{\partial k}{\partial x_{f}}\right]+D \\
\frac{\partial k}{\partial t}+U_{i} \frac{\partial k}{\partial x_{i}}=f_{1} C_{\varepsilon 1} \frac{\varepsilon}{k} v_{t}\left(\frac{\partial U_{i}}{\partial x_{j}}+\frac{\partial U_{j}}{\partial x_{i}}\right) \frac{\partial U_{i}}{\partial x_{j}}-f_{2} C_{\varepsilon 2} \frac{\varepsilon^{2}}{k}+\frac{\partial}{\partial x_{j}}\left[\left(v+\frac{v_{t}}{\sigma k}\right) \frac{\partial k}{\partial x_{f}}\right]+E \\
v_{t}=f_{\mu} C_{\varepsilon \mu} \frac{k^{2}}{\varepsilon}
\end{gathered}
$$

where $U_{i}$ is the mean velocity vector of the flow, $v_{t}$ is turbulent kinematic viscosity, $f_{\mu}$ is damping function, $C_{\mu}$ is model constant, $k$ is turbulent kinetic energy and $\varepsilon$ is energy dissipation rate. In a comparison to the standard closure models, the low-Re k- $\varepsilon$ equations contain damping functions $f_{\mu}, f_{1}$ and $f_{2}$, destruction terms $D$ and $E$, and molecular 
diffusion terms. Also, the values of model constants, $C_{\mu}, \mathrm{C}_{\varepsilon 1}$ and $C_{\varepsilon 2}$ are to be specified by the user and are different for different models. The model constants for Low-Re k- $\varepsilon$ model are: $C_{\mu}=0.09, C_{\varepsilon 1}=1.50, C_{\varepsilon 2}=1.90, \sigma_{k}=1.40$ and $\sigma_{\varepsilon}=1.40$. In addition to that of the terms $D=0$ and $E=0$. The damping functions considered in this model are

$$
\begin{aligned}
& f_{u}=\left[1-\exp \left(\frac{-y^{k}}{14}\right)\right]^{2}\left[1+\frac{5}{R_{T}^{(3 / 4)}} \exp \left\{-\left(\frac{R_{T}}{200}\right)^{2}\right\}\right] \\
& f_{\varepsilon 1}=1 \\
& f_{\varepsilon 2}=\left[1-\exp \left(\frac{-y^{k}}{3.1}\right)\right]^{2}\left[1+0.3-\left(\frac{R_{T}}{6.5}\right)^{2}\right]
\end{aligned}
$$

where $y^{k}=u_{\varepsilon} \frac{y}{v}$ and $R_{T}=\frac{k^{2}}{v \varepsilon}[28]$.

For more details on low-Re turbulence models, model constants and notations readers are advised to refer ANSYS ${ }^{\mathrm{TM}}$ Fluent manual [29].

\subsection{Mesh Generation}

The next step is the mesh generation in our domain and around the tubes. As can be seen in Fig. 2, the mesh is also divided into three parts to reach the maximum accuracy and minimum computational time. The mesh is $3 \mathrm{D}$ and except the edge of the winglet where tetrahedral elements are used, all other parts use a structured mesh. Also for reaching the desirable accuracy, the result convergence has been checked by using different numbers of elements: $382351,507256,725665$ and 983683 , for a case with an angle of attack $b=30^{\circ}$ at Reynolds number 400 (chosen arbitrarily). Table 2 shows the numerical results and the average deviation for three different meshes for $\mathrm{Re}=400$. As expected, this difference (error) decreases as the mesh becomes finer. However, it was found that the error between the results achieved with the mesh with 725665 and 983683 elements was less than $0.1 \%$ regarding the Friction Factor and less than $2 \%$ regarding the Colburn Factor. Based on the validation and in order to keep a balanced compromise between computational time and solution accuracy, the mesh with 725665 elements was selected.

Table 2 Summary of the grid independence

\begin{tabular}{lrcc}
\hline \multicolumn{2}{l}{ Number of elements } & Friction Factor, f & $\begin{array}{c}\text { Different } \\
\text { percentage for f }\end{array}$ \\
\hline MESH 1 & 382351 & 0.07447 & - \\
MESH 2 & 507256 & 0.07462 & $0.21 \%$ \\
MESH 3 & 725665 & 0.07483 & $0.29 \%$ \\
MESH 4 & 983683 & 0.07482 & $-0.02 \%$ \\
\hline
\end{tabular}




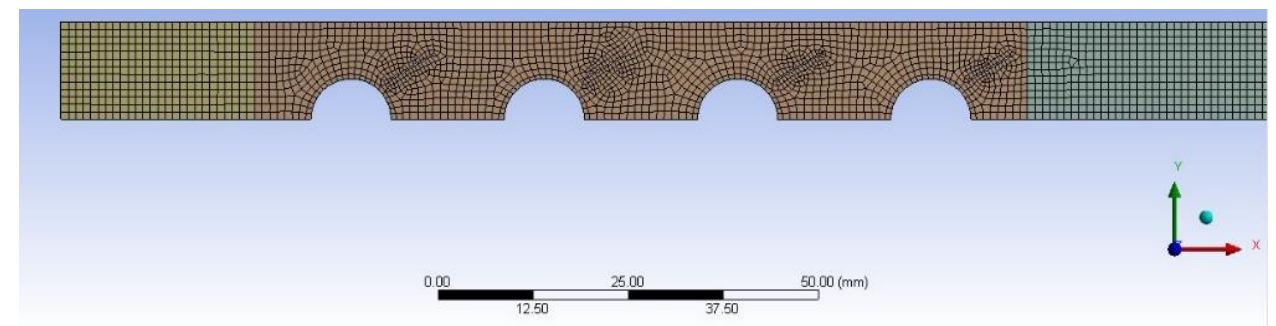

Fig. 2 Mesh generation on the computational model of CHE with delta winglet VG

\subsection{Simulating Steady-State Tests}

Steady-state simulations were performed using FLUENT software with parameters set as follows. The first order implicit solver with the steady option ( $\mathrm{K}$ and $\varepsilon$, parameter Turbulent Kinetic Energy $=1 \mathrm{~m}^{2} / \mathrm{s}^{3}$, Turbulent Dissipation Rate $=1 \mathrm{~m}^{2} / \mathrm{s}^{3}$ ) was selected together with the standard wall function, while other options remained as by default, with energy function. COUPLED algorithm based on [5, 30, 31] was used to calculate pressure-velocity coupling, pressure discretization and the momentum discretization were the first order upwind discrete mode. The force and momentum data are recorded in every step. Due to the small fin pitch and low fluid velocity, the incompressible flows in the airside passages turn out as laminar streams [32].

\subsection{Validation}

Validation of the numerical study in this research has been done by comparison of the CFD results with other researcher's experiments. For this phase, the experiment carried by Wang et al. [33] was selected. Figure 3 illustrates the comparison between the

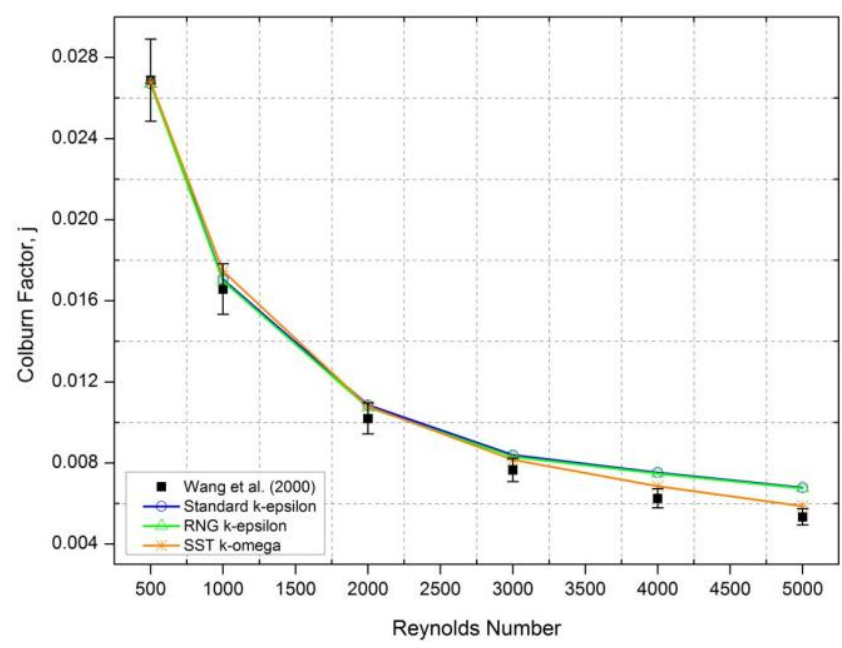

Fig. 3 Comparison of experimental results presented by Wang [33] and present work 
experimental and numerical results for the Colburn factor on the air side. As can be seen, there is a good agreement between the numerical results and experimental data, which reveals the consistency of numerical simulation introduced in this study. The highest difference between the numerical results obtained by the current model and the experimental data for the Colburn $\mathrm{J}$ factor were about $12 \%$.

\section{RESULTS AND DISCUSSION}

The parametric study was performed in order to investigate the most important design variable in the heat exchanger performance and choose the most appropriate optimization algorithm. The design variables are the angle of attack $(\theta)$, length of the VGs $(l)$, horizontal position of the VGs based on the tube center $\left(X_{v}\right)$ and vertical position of the VGs based on the tube center $\left(Y_{v}\right)$. To investigate the degree of importance of each variable before the design optimization is carried out, the effect of each design variable on the pressure drop, Nusselt number and overall heat transfer performance was examined by varying only one variable among the baseline parameters. For example, for examining the effect of angle of attack on the heat transfer and flow characteristics of the fin-and-tube compact heat exchangers (FTCHE) with delta winglets, the angle of attack varies from $10^{\circ}$ to $60^{\circ}$ and the other parameters remain the same as listed in Table 1.

\subsection{Effect of angle of attack}

In the present section, a comparative study of the effects of the angle of attack of vortex generator on the performance of compact heat exchangers is evaluated as the parametric design input variable for the optimization algorithm. The angle varies from $10^{\circ}$ to $60^{\circ}$ and the other parameters are kept the same as in Table 1 . The graph of Nusselt number, friction factor, and overall performance of CHEs are conducted by numerical method.

Figure 4 shows the average Nusselt number and the friction factor with air frontal velocity for various angles of attack. It can be seen that Nusselt number increases with the increase in angle of attack up to $30^{\circ}$ and then starts to decrease, while the friction factor increases in all angles. Figure 4 shows that the maximum values of convective heat transfer rate occur in the case of angle equal to $30^{\circ}$. The results show the minimum values of the Nusselt number created for the angle of $60^{\circ}$. The results have shown that the average Nusselt number decreases significantly with the increase of angle. Figure 4 shows the effects of the angle of attack on friction factor. The f factor increases with the increase in the angle of attack. The results displayed the minimum values founded for the angle of $0^{\circ}$. It is clearly shown that larger values of angles of attack may lead to the higher friction factor, and smaller angle may lead to smaller flow resistance. 

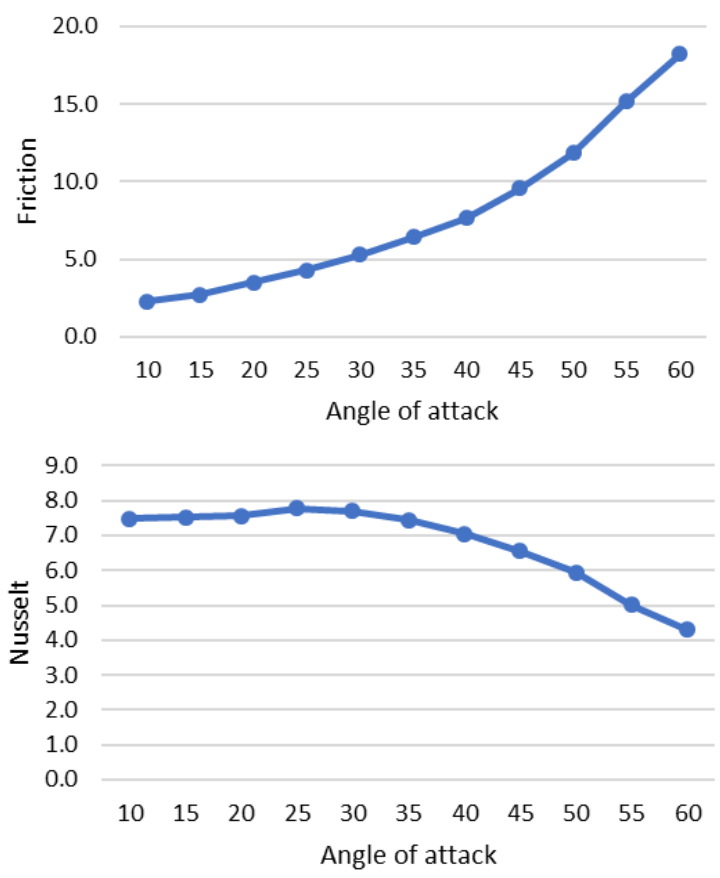

Fig. 4 Effect of angle of attack of VGs on the friction factor and average Nusselt number

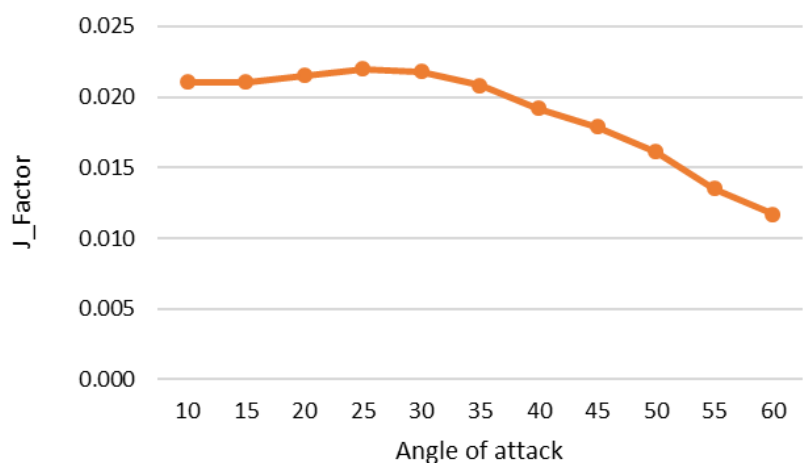

Fig. 5 Effect of angle of attack of VGs on the on overall performance criteria

Figure 5 shows the effect of angle of attack of VGs on the overall performance criteria (JF factor). It can be seen that the JF factor decreases with increase in angle of attack.

\subsection{Effect of the length of the vortex generator}

The parametric study is performed in order to investigate the importance of wing length of vortex generator as a design variable in the heat exchanger performance when the other parameters are kept the same. The effect of the wing length on the Nusselt number and friction factor is shown in Fig. 6. The results for various VG length are plotted as a function 
of the Nusselt number and Friction factor. The Nusselt number significantly decreases with the increase of the length, whereas the friction factor decreases with the increase of length. The highest values of Friction factor occur at the length of $7 \mathrm{~mm}$ and this due to a blockage that these VGs make in front of the flow. It's totally logical that most resistance is on the biggest block. The highest Nusselt number is at the length of $5 \mathrm{~mm}$ and this paradox between the Friction factor and Nusselt number, again shows the significance of optimizing for the VGs.

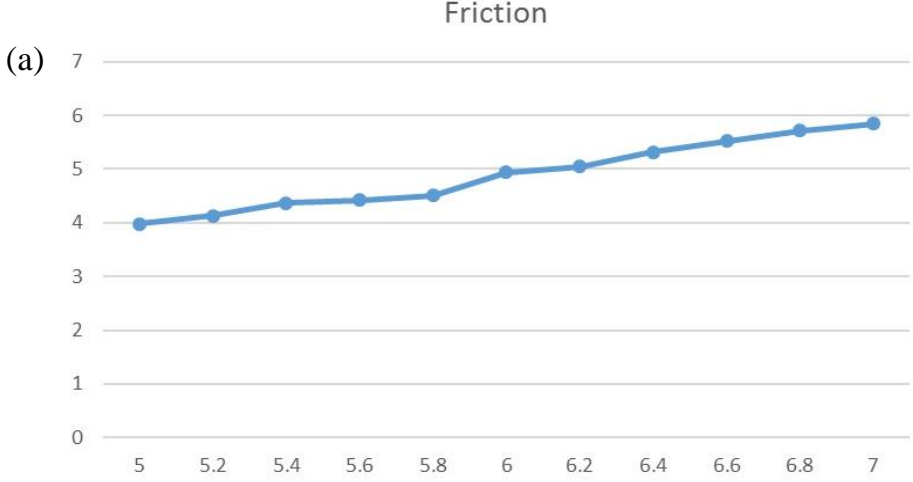

(b)

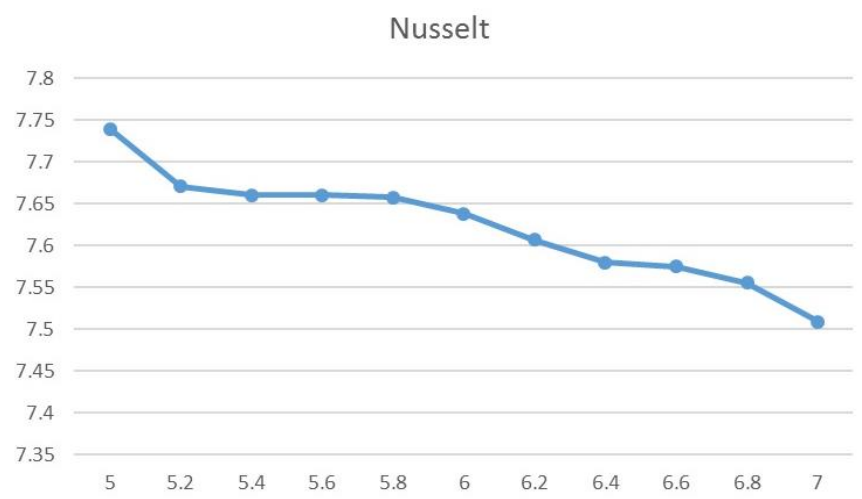

Fig. 6 Influence of winglet length: (a) on friction factor, (b) on Nu number

Figure 7 shows the variations of the overall performances for different VGs length. The JF factor decreases with an increase in VGs length. It is noted obviously that the augment on pressure loss is smaller than the improvement in heat transfer, which leads to the positive effects of making the VGs smaller. 


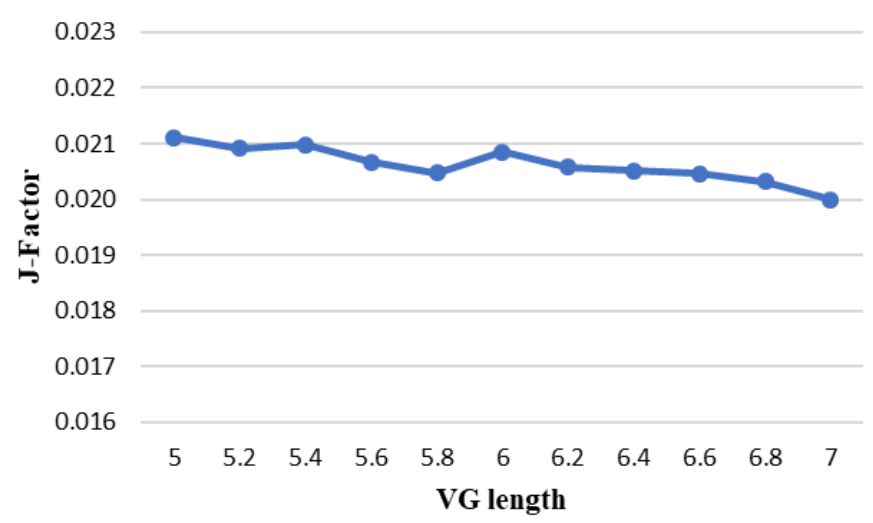

Fig. 7 Effect of VG length in on overall performance criteria

\subsection{Effect of the horizontal position of the vortex generator}

Examining the effect of the horizontal position of the VGs based on distance from the centre of the tubes (Fig. 8), it is seen that the distance varies from $4.55 \mathrm{~mm}$ to $6.4 \mathrm{~mm}$, and the other parameters are kept the same for the designs of compact heat exchangers. Figure 9 shows the effect of horizontal position on both the Nusselt number and friction factor. It can be seen that the Nusselt number decreases when the VGs move away from the tubes, but the rate of decreasing become less at $5.825 \mathrm{~mm}$. Also, a downward trend in friction factor is achieved at all positions. The only exception is at $5.285 \mathrm{~mm}$ in which the Friction has raised, but then again, it started to decrease for the rest of the positions. According to Fig. 9(a), the maximum values of Friction factor are achieved when the VGs positioned at $4.725 \mathrm{~mm}$ from the centre of the tubes. Moreover, Fig. 9(b) indicated that the maximum Nusselt number is achieved for the nearest position of the VGs. Then it started to decrease very sharply to $5.825 \mathrm{~mm}$ and after this point, the variation becomes insignificant.

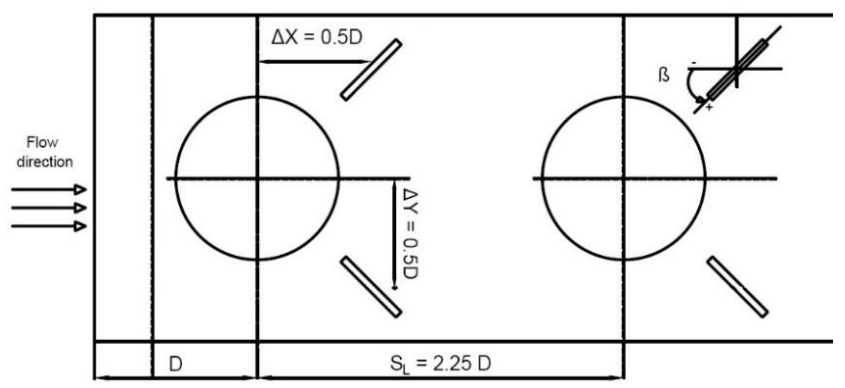

Fig. 8 Definition of Horizontal and Vertical position of VGs 
Heat Transfer Enhancement and Pressure Drop for Fin-and-Tube Compact Heat Exchangers with Delta... 243

(a)

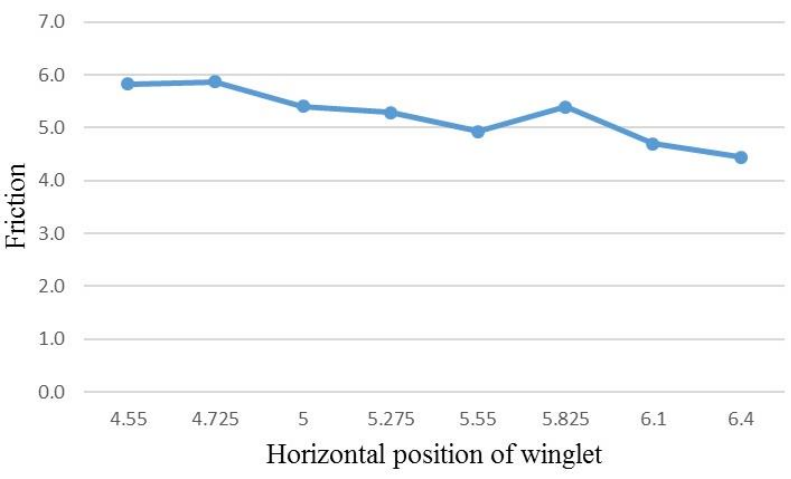

(b)

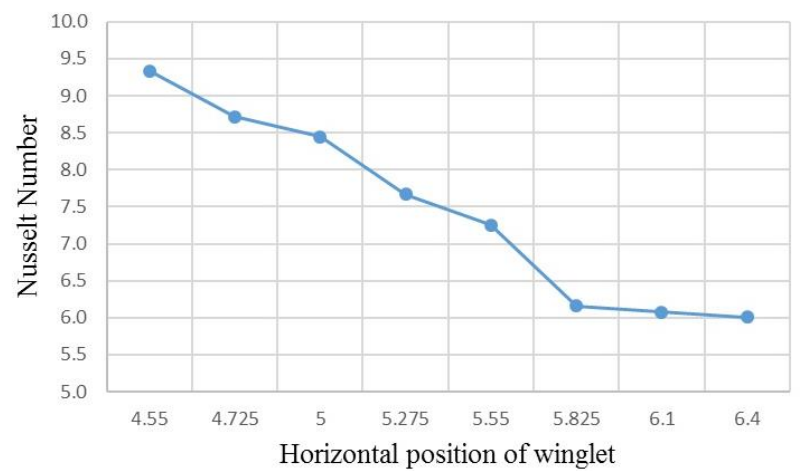

Fig. 9 Effect of the horizontal position of the winglet on (a) Friction, (b) Nusselt number

Figure 10 shows the maximum values of J_Factor for the different horizontal position from the centre of the tubes. The overall performance of FTCHE with delta winglet significantly decreased by moving longitudinally from the centre of the tubes

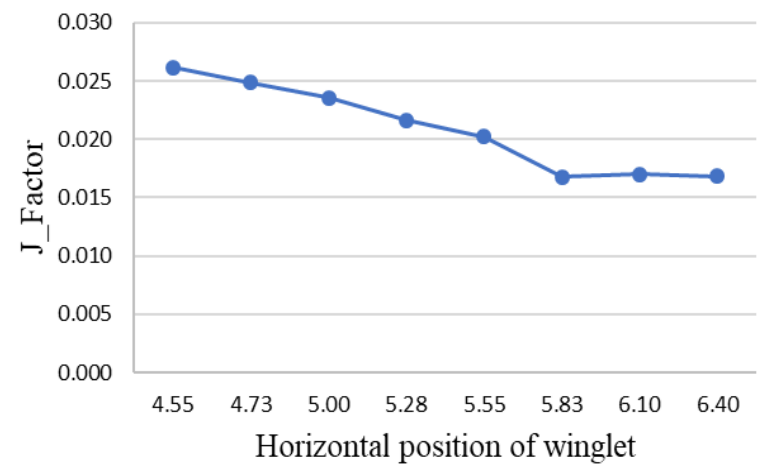

Fig. 10 Variation of values of overall performance based on horizontal position

According to Fig. 10, at the range of the various horizontal position of the present study, the maximum values of JF factor are achieved for the nearest VGs. For the far 
positions, the J_Factor values are almost same and without considerable changes. This because of the boundary layer and whenever the VGs are in the boundary layer, they disturb this boundary layer more so they have more influence on the total performance of FTCHE.

\subsection{Effect of the vertical position of the vortex generator}

Examining the effect of the vertical position of the VGs based on distance from the centre of the tubes (Fig. 8), it is seen that the distance varies from $4.55 \mathrm{~mm}$ to $6.4 \mathrm{~mm}$, and the other parameters are kept the same for the designs of compact heat exchangers based on table 1 . Figure 11 shows the effect of vertical position on both the Nusselt number and friction factor. It can be seen that the Nusselt number decreases when the VGs move away from the tubes, but the rate of decreasing become less at $6.1 \mathrm{~mm}$. But there is an upward trend in the friction factor at all positions. According to Fig. 11(a), the maximum values of Friction factor are achieved when the VGs positioned at the farthest possible position, i.e. $6.375 \mathrm{~mm}$ from the centre of the tubes.

(a)
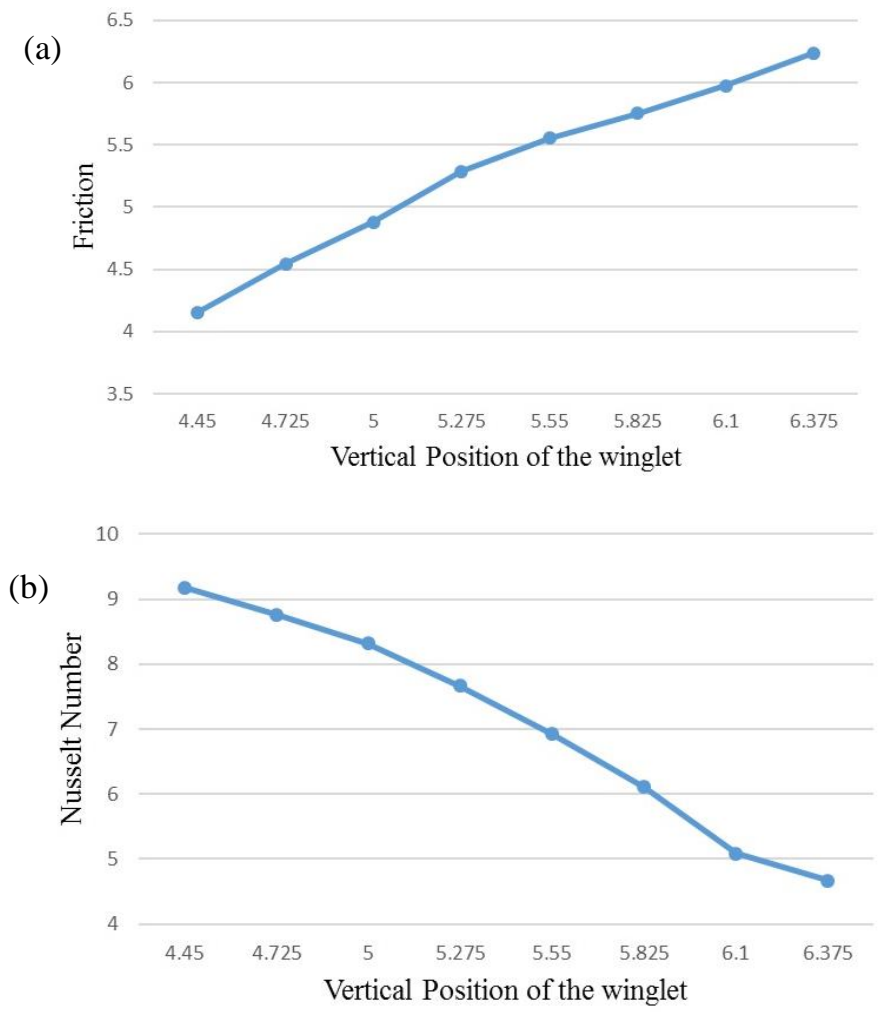

Fig. 11 Effect of the vertical position of the winglet on (a) Friction, (b) Nusselt number 
Moreover, Fig. 11(b) indicates that the maximum Nusselt number is achieved for the nearest position of the VGs. Then it starts to decrease very sharply to $6.1 \mathrm{~mm}$ and after this point, the variation becomes insignificant.

Figure 12 shows the maximum values of J_Factor for the different vertical position from the centre of the tubes. The overall performance of FTCHE with delta winglet significantly decreased by moving longitudinally from the centre of the tubes.

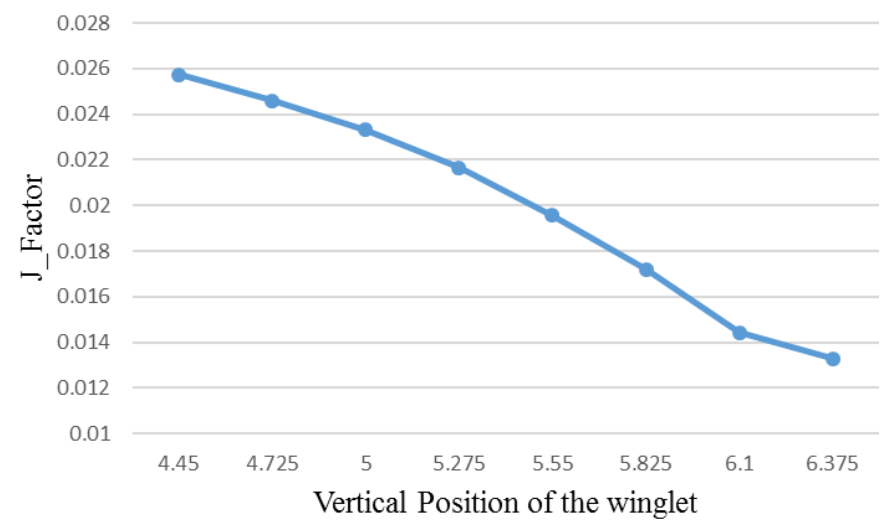

Fig. 12 Variation of values of overall performance based on the vertical position

According to Fig. 12, at the range of the various horizontal position of the present study, the maximum values of JF factor are achieved for the nearest VGs. For the far positions, the J_Factor values are almost same and without considerable changes. This because of the boundary layer and whenever the VGs are in the boundary layer, they disturb this boundary layer more so they have more influence on the total performance of FTCHE.

In addition, according to Fig. 11(b) and Fig. 12, the results show that at the same position, the Nusselt number and J_F factor have the similar trend, which indicates that the overall performance of the system is dominated by convective heat transfer.

\section{CONCLUSIONS}

This study presents a numerical investigation of the effect of different parameters on the thermohydraulic performance of compact heat exchangers with vortex generators. The parameters investigated in this study are the angle of attack, length of the winglet, horizontal and vertical placement of the winglet. The main outcomes of this study are as follows:

- This study shows the importance of the VGs and how they affect the heat transfer rate and pressure drop.

- The heat transfer rate of the compact heat exchangers improves in lower angle of attack as well as lower length. But it decreases by putting the VGs far from the tubes.

- The pressure drop has more consistent behavior and shows in all cases a stable trend. Increasing the angle of attack and length of the VGs will result in more pressure drop. In vertical positions far from the tubs, also pressure drop increases. And the horizontal position has the least effect on the pressure drop despite a slight improvement in case of a bigger gap. 
- In all cases, the overall performance of the compact heat exchangers based on J_Factor decreases with the increase of the aforementioned parameters.

- This study shows that, for improving the thermohydraulic efficiency of the compact heat exchangers with vortex generators, many parameters must be considered simultaneously and it is necessary to use a multi-objective optimizer to reach the optimum configuration.

Acknowledgement: The authors gratefully acknowledge the support by the faculty of mechanical engineering, Universiti Teknologi Malaysia, for providing a research grant for this investigation.

\section{REFERENCES}

1. Wang, C.-C., Liaw, J.-S., Yang, B.-C., 2011, Airside performance of herringbone wavy fin-and-tube heat exchangers - data with larger diameter tube, International Journal of Heat and Mass Transfer, 54(5-6), pp. 1024-1029.

2. Yun, R., Kim, Y., Kim, Y., 2009, Air side heat transfer characteristics of plate finned tube heat exchangers with slit fin configuration under wet conditions, Applied Thermal Engineering, 29(14-15), pp. 3014-3020.

3. Phan, T.-L., Chang, K.S., Kwon, Y.C., Kwon, J.-T., 2011, Experimental study on heat and mass transfer characteristics of louvered fin-tube heat exchangers under wet condition, International Communications in Heat and Mass Transfer, 38(7), pp. 893-899.

4. Lin, Z.M., Wang, L.B., Zhang, Y.H., 2014, Numerical study on heat transfer enhancement of circular tube bank fin heat exchanger with interrupted annular groove fin, Applied Thermal Engineering, 73(2), pp. 1465-1476.

5. Joardar, A., Jacobi, A.M., 2008, Heat transfer enhancement by winglet-type vortex generator arrays in compact plain-fin-and-tube heat exchangers, International Journal of Refrigeration, 31(1), pp. 87-97.

6. Huisseune, H., T'Joen, C., Jaeger, P.De, Ameel, B., Schampheleire, S.De, Paepe, M.De., 2013, Performance enhancement of a louvered fin heat exchanger by using delta winglet vortex generators, International Journal of Heat and Mass Transfer, 56(1-2), pp. 475-487.

7. Tian, L., He, Y., Tao, Y., Tao, W., 2009, A comparative study on the air-side performance of wavy finand-tube heat exchanger with punched delta winglets in staggered and in-line arrangements, International Journal of Thermal Sciences, 48(9), pp. 1765-1776.

8. Fiebig., M., 1995, Vortex generators for compact heat exchangers, J. Enhanced Heat Transfer, 2, pp. 43-61.

9. Jacobi, A.M., Shah, R.K., 1995, Heat transfer surface enhancement through the use of longitudinal vortices: A review of recent progress, Experimental Thermal and Fluid Science, 11(3), pp. 295-309.

10. Jayavel, S., Tiwari, S., 2010, Effect of tube spacing on heat transfer performance of staggered tube bundles in the presence of vortex generators, Journal of Enhanced Heat Transfer, 17(3), pp. 271-291.

11. Akbari, M.M., Murata, D.A., Mochizuki, D.S., Saito, H., Iwamoto, K., 2009, Effects of Vortex Generator Arrangements on Heat Transfer Enhancement over a Two-Row Fin-and-Tube Heat ExchangerI, Journal of Enhanced Heat Transfer, 16(4), pp. 315-329.

12. Joardar, A., Jacobi, a. M., 2007, A Numerical Study of Flow and Heat Transfer Enhancement Using an Array of Delta-Winglet Vortex Generators in a Fin-and-Tube Heat Exchanger, Journal of Heat Transfer, 129(9), pp. 1156-1167.

13. Hwang, S.W., Kim, D.H., Min, J.K., Jeong, J.H., 2012, CFD analysis of fin tube heat exchanger with a pair of delta winglet vortex generators, Journal of Mechanical Science and Technology, 26(9), pp. 2949-2958.

14. Lemouedda, A., Breuer, M., Franz, E., Botsch, T., Delgado, A., 2010, Optimization of the angle of attack of delta-winglet vortex generators in a plate-fin-and-tube heat exchanger, International Journal of Heat and Mass Transfer, 53(23-24), pp. 5386-5399.

15. Wu, J.M., Tao, W.Q., 2011, Impact of delta winglet vortex generators on the performance of a novel fintube surfaces with two rows of tubes in different diameters, Energy Conversion and Management, 52(89), pp. 2895-2901.

16. Gorji, M., Mirgolbabaei, H., Barari, A., Domairry, G., Nadim, N., 2011, Numerical analysis on longitudinal location optimization of vortex generator in compact heat exchangers, International Journal for Numerical Methods in Fluids, 66(6), pp. 705-713. 
17. Tiggelbeck, S., Mitra, N.K., Fiebig, M., 1994, Comparison of Wing-Type Vortex Generators for Heat Transfer Enhancement in Channel Flows, Journal of Heat Transfer, 116(4), pp. 880-885.

18. He, Y.L., Han, H., Tao, W.Q., Zhang, Y.W., 2012, Numerical study of heat-transfer enhancement by punched winglet-type vortex generator arrays in fin-and-tube heat exchangers, International Journal of Heat and Mass Transfer, 55, pp 5449-5458.

19. Torii, K., Kwak, K.M., Nishino, K., 2002, Heat transfer enhancement accompanying pressure-loss reduction with winglet-type vortex generators for fin-tube heat exchangers, International Journal of Heat and Mass Transfer, 45(18), pp. 3795-3801.

20. Lin, C.N., Jang, J.Y., 2002, Conjugate heat transfer and fluid flow analysis in fin-tube heat exchangers with wave-type vortex generators, Journal of Enhanced Heat Transfer, 9(3-4), pp. 123-136.

21. Lin, C.-N., Liu, Y.-W., Leu, J.-S., 2008, Heat Transfer and Fluid Flow Analysis for Plate-Fin and Oval Tube Heat Exchangers With Vortex Generators, Heat Transfer Engineering, 29(7), pp. 588-596.

22. Jang, J.Y., Hsu, L.F., Leu, J.S., 2013, Optimization of the span angle and location of vortex generators in a plate-fin and tube heat exchanger, International Journal of Heat and Mass Transfer, 67, pp. 432-444.

23. Dupont, F., Gabillet, C., Bot, P., 2003, Experimental Study of the Flow in a Compact Heat Exchanger Channel With Embossed-Type Vortex Generators, Journal of Fluids Engineering, 125(4), pp. 701-709.

24. Zhou, G., Ye, Q., 2012, Experimental investigations of thermal and flow characteristics of curved trapezoidal winglet type vortex generators, Applied Thermal Engineering, 37, pp. 241-248.

25. Tang, L.-H., Min, Z., Xie, G.-N., Wang, Q.-W., 2009, Fin Pattern Effects on Air-Side Heat Transfer and Friction Characteristics of Fin-and-Tube Heat Exchangers with Large Number of Large-Diameter Tube Rows, Heat Transfer Engineering, 30(3), pp. 171-180.

26. Gholami, A.A., Wahid, M.A., Mohammed, H.A., 2014, Heat transfer enhancement and pressure drop for fin-and-tube compact heat exchangers with wavy rectangular winglet-type vortex generators, International Communications in Heat and Mass Transfer, 54, pp. 132-140.

27. Jagadeesh, P., Murali, K., 2005, Application of low-re turbulence models for flow simulations past underwater vehicle hull forms, Journal of Naval Architecture and Marine Engineering, 2(1), pp. 41-54.

28. Ferrouillat, S., Tochon, P., Garnier, C., Peerhossaini, H., 2006, Intensification of heat-transfer and mixing in multifunctional heat exchangers by artificially generated streamwise vorticity, Applied Thermal Engineering, 26(16), pp. 1820-1829.

29. 2016, Ansys Fluent 17.0 Tutorial Guide.

30. Sanders, P., Thole, K., 2006, Effects of winglets to augment tube wall heat transfer in louvered fin heat exchangers, International Journal of Heat and Mass Transfer, 49(21-22), pp. 4058-4069.

31. Allison, C., Dally, B., 2007, Effect of a delta-winglet vortex pair on the performance of a tube-fin heat exchanger, International Journal of Heat and Mass Transfer, 50(25-26), pp. 5065-5072.

32. Gentry, M.C. and Jacobi, A.M., 1997, Heat transfer enhancement by delta-wing vortex generators on a flat plate: Vortex interactions with the boundary layer, Experimental Thermal and Fluid Science, 14(3), pp. 231-242.

33. Wang, C.-C., Chi, K.-Y., 2000, Heat transfer and friction characteristics of plain fin-and-tube heat exchangers, part I: new experimental data, International Journal of Heat and Mass Transfer, 43(15), pp. 2681-2691. 